\title{
First report of Carpesium abrotanoides L. as a natural host plant for pepper vein yellows virus in China
}

\author{
Xuehui Liu ${ }^{1}$ - Chun $\mathrm{Li}^{1}$ - Shiping Wu ${ }^{1} \cdot$ Lishuang Wang ${ }^{1}$ (D) \\ Received: 14 July 2020 / Accepted: 26 August 2020 / Published online: 31 August 2020 \\ (C) Società Italiana di Patologia Vegetale (S.I.Pa.V.) 2020
}

Keywords Pepper vein yellows virus · Carpesium abrotaniodes L. · Natural host

Pepper vein yellows virus (PeVYV) has caused disease epidemics in Solanaceae crops in Europe (Villanueva et al. 2013), Asia (Zhang et al. 2015) and Africa (Knierim et al. 2013). In 2019, weeds (Carpesium abrotanoides L.), which were identified by sequence identity of the $5.8 \mathrm{~S}$ ribosomal RNA and exhibited virus-like symptoms, were collected from a pepper field in Guizhou city. Six plants were collected and the pathogen was identified by high throughput small RNA sequencing. One leaf from each sampled weed was pooled and total RNA was extracted by Trizol reagent. Small RNA libraries were constructed and sequenced by Solexa sequencer (Illumina Hiseq 2000, USA). High quality small RNA reads were assembled to contigs using software Velvet 1.0.5. The contigs were identified by BLASTn against the database of viral genomes in GenBank (http://www.ncbi.nlm.nih.gov/ genomes/GenomesHome.cgi?). Ten contigs of 85-235 bp in size showed high nucleotide sequence identity $(>95 \%)$ to partial sequences of reference genomes of PeVYV (NC_015050. 1). To confirm the occurrence of PeVYV in symptomatic weeds, RT-PCR was performed to amplify a partial fragment of the PeVYV movement protein gene using the specific primer pair designed for this study (CABF: 5'ATGGAAATGGTGGATCACGTAAC-3', CABR: 5'CCTCCGCTGTGGAAGAGGATTCA-3') on all six symptomatic weed samples and one healthy pepper plant as a negative control. A DNA fragment of the expected size (348 bp) was amplified from two symptomatic $C$. abrotanoides plants, but not from healthy pepper. One of the amplicons was purified and directly sequenced. The amplicon (GenBank accession number MK685275) showed 99.14\% nucleotide sequence identity with PeVYV isolate HN from China (KP326573). In addition, northern blot analysis using a digoxigenin-labeled PCR fragment produced using the CABF/CABR primer to probe total RNA identified PeVYV in one of PeVYV positive weed plant. This is the first report of C. abrotanoides L. as a natural host of PeVYV.

Funding This study was fund by Guizhou Science and Technology Department ([2017]01183, [2017]2549) and National key fund of Research and Development [2018YFD0200100].

\section{References}

Knierim D, Tsai WS, Kenyon L (2013) Analysis of sequences from field samples reveals the presence of the recently described pepper vein yellows virus (genus Polerovirus) in six additional countries. Arch Virol 158:1337-1341

Villanueva F, Castillo P, Font MI, Alfaro-Fernández A, Moriones E, Navas-Castillo J (2013) First report of Pepper vein yellows virus infecting sweet pepper in Spain. Plant Dis 97(9):1261

Zhang SB, Zhao ZB, Zhang DY, Liu Y, Luo XW, Liu J, Wu LF, Peng J (2015) First report of Pepper vein yellows virus infecting red pepper in mainland China. Plant Dis 99(8):1190

Publisher's note Springer Nature remains neutral with regard to jurisdictional claims in published maps and institutional affiliations.
Lishuang Wang

quixuming118@126.com

1 Plant Protection Institute of Guizhou Province Academy of Agricultural Sciences, Guiyang 550009, China 